\title{
A DISCIPLINA DE FILOSOFIA NO BRASIL DESDE OS JESUÍTAS ATÉ A LDB N ${ }^{\circ}$ 9394/96: PERSPECTIVAS HISTÓRICAS
}

Yvisson Gomes dos Santos*

Resumo: o presente artigo trata sobre a historicização do ensino da disciplina de filosofia no Brasil, desde a cultura educacional jesuítica até a atual LDB 9304/96. Essa pesquisa trouxe-nos efetivamente um olhar dinâmico da extemporaneidade e contemporaneidade de tal disciplina, no qual se observou que seu percurso foi traçado por avanços significativos através das modificações político-educacionais no Brasil.

Palavras-chave: Educação. Filosofia. Ensino Médio. Jesuítas. LDB 9394/96.

Resumen: En este artículo se describe la historicidad de la filosofía de disciplina de la educación en Brasil, a partir de la cultura educativa de la Compañía hasta que la corriente de LDB 9304/96. Esta investigación realmente nos trajo un aspecto dinámico de lo avanzado y contemporaneidad de esta disciplina, en la que señaló que su ruta fue trazada por un progreso significativo a través de cambios políticos y educativos en Brasil.

Palabras claves: Educación. Filosofía. Escuela Secundaria. Jesuitas. LDB 9394/96.

A Filosofia inicia a sua odisseia pelo Brasil, em 1553, período em que o país era colônia de Portugal, de onde reproduzia todo modelo educacional e político. Neste período foi atribuída aos padres da Companhia de Jesus, ordem religiosa da Igreja Católica, a responsabilidade de conduzir as ações educacionais na Colônia. A principal função dos Jesuítas era catequizar e instruir os índios, os negros e os colonos degredados que mais tarde seriam a classe dominante da colônia (PAIM, 1984).

\footnotetext{
* Mestrado em Educação pela Universidade Federal de Alagoas, Brasil (2015). Professor Tutor a distância - CIED/UFAL da Universidade Federal de Alagoas, Brasil e Membro do GT Filosofia da Educação/Ensino de Filosofia (UFAL), Brasil. E-mail.: yvissongomes@hotmail.com
}

Sendo assim, foi transplantada para o Brasil a mesma proposta pedagógica da Companhia de Jesus: o Ratio Studiorum ${ }^{1}$, "que sintetizava a experiência pedagógica dos Jesuítas, regulando os cursos, programas, métodos e disciplinas das escolas da companhia" (PAIM, 1984, p.210). Neste contexto, a Filosofia é dada nos cursos de nível superior (studia superiora), corres-

\footnotetext{
1 "Conjunto de normas didáticas para os professores da ordem, criadas entre os anos de 1560 e 1599, que tinham o objetivo de transportar o estudante para um ambiente diferente daquele em que nascera, levando-o a imergir, inclusive fazendo-o utilizar sistematicamente o latim, em uma cultura depurada da Antiguidade clássica, de modo a moldar o "bom cristão", preparando-o para a vida em sociedade e para o sacerdócio ao mesmo tempo" (VAINFAS apud BARBOSA, 2005, p.23).
}

SANTOS, Yvisson Gomes dos. A disciplina de filosofia no brasil desde os jesuítas até a LDB n ${ }^{\circ}$ 9394/96: perspectivas históricas. Revista Sul-Americana de Filosofia e Educação. Número 27: nov/2016-abr/2017, p. 186-200. 
pondentes aos cursos de Teologia e Filosofia.

A duração do curso de Filosofia era apenas de dois anos e estudava-se principalmente as ideias do pensador Aristóteles, como também alguns filósofos que versavam sobre a moral tais como Cícero, Santo Agostinho e Santo Tomás de Aquino. No entanto, neste período não se estudava toda e qualquer filosofia, somente os filósofos que enfatizavam a ideologia da Igreja Católica, que se encontrava extremamente abalada pela reforma protestante e pelo movimento renascentista que ganhava força na Europa. As leituras eram rigorosamente selecionadas, assim como os professores eram monitorados, desta forma eles não poderiam colocar ideias entendidas como "perniciosas" nas mentes de seus alunos, o que poderia colocar em risco as estruturas dos dogmas católicos. Para exemplificar esta vigilância rigorosa, a $15^{a}$ regra da Ratio studiorum prescreve "[...] se alguns forem amigos de novidade ou de espírito demasiado livre, devem ser afastados sem hesitação do serviço docente" (PAIM, 1984, p.210).

Naquela época, a Igreja Católica estava perdendo seus fiéis para a burguesia adepta ao protestantismo, que questionava os seus dogmas e para o movimento renas- centista, que exaltava as criações humanas, como nas artes (a música e as pinturas) e nas ciências (medicina, física e astrologia).

[...] a Companhia de Jesus é fundada exatamente na época em que se afirmava o movimento da reforma tridentina, visando, seja o fortalecimento moral da Igreja contra a influência da mentalidade renascentista, seja o restabelecimento do espírito de autoridade abalado pela reforma protestante (ALVES, 2002, p.11).

Temendo a influência que as ideias "perniciosas" do pensamento moderno pudessem exercer sobre a Colônia, a Cia. de Jesus passou a restringir leituras de alguns pensadores como Rousseau, Locke e Hobbes, Espinosa e Voltaire, dentre outros (HORN, 2000).

Os cursos eram oferecidos apenas aos "homens de bem" da colônia, ou seja, senhores ricos, fazendeiros e proprietários de terras. Brancos pobres, negros e índios eram excluídos em sua grande maioria, sendo que apenas alguns poucos possuíam acessos à educação e, mesmo assim, apenas aos cursos elementares (ler e escrever) $e$ aos de humanidade (curso de letras, filosofia e latim). "Os cursos que permitiam um grau mais elevado de cultura, formação e profissionalização, os studia superiora, que compreendiam os cursos de Filosofia e Teologia, estavam reservados aos filhos dos 
senhores ricos e proprietários da colônia" (ALVES, 2002, p. 12).

No que tange à metodologia de ensino, esta entendida como os processos didáticos que eram adotados para transmitir conhecimentos $e$ as motivações pedagógicas utilizadas para assegurar o êxito do esforço educativo, pode-se destacar dois aspectos principais que caracterizam a metodologia no Brasil Colônia (RIBEIRO apud BARBOSA, 2005). Quando da organização do ensino nos cursos acima mencionados - humanidades, filosofia e teologia, o Ratio preconizava que:

[...] a preleção do professor deveria ser o centro de gravidade do sistema didático. O segundo aspecto enfatizado era o exercício da memória, onde a competição era incentivada com o intuito de hierarquização da classe e a premiação ocupava lugar de destaque. Aliados a esses dois aspectos, o ensino e a vivência da religião deviam ser o corolário de todo esse processo (RIBEIRO apud BARBOSA, 2005, p.25).

Percebe-se que nesta época, a Filosofia possuía somente um caráter propedêutico $e$ livresco, servindo exclusivamente aos interesses da classe dominante, assumindo, outrossim, um caráter diverso do realmente afeto à Filosofia, qual seja, tornar o pensamento humano autônomo incentivar a reflexão crítica.
Como Portugal havia se afastado do pensamento moderno europeu devido ao temor da difusão das ideias iluministas que ameaçavam os dogmas católicos, o reino lusitano teve que se adaptar às mudanças políticas e econômicas ocorridas na Europa para não ficar atrás. No século XVIII a Metrópole portuguesa passava por uma profunda crise econômica e dependia financeiramente da Inglaterra. Tendo em vista esta situação, Portugal iniciou um conjunto de reformas para retirar o país da dependência inglesa (PAIM, 1984).

Sebastião José de Carvalho, o Marques de Pombal (1750) foi o homem escolhido para retirar o reino lusitano desta crise. Iniciando um conjunto de reformas, começou por aproximar o reino com a ideologia iluminista e liberal que dominava a Europa. Com isso, Pombal expulsou a Companhia de Jesus de Portugal e de suas colônias, para assim iniciar as reformas no campo educacional para implantar as ideias iluministas $e$, que consequentemente seriam copiadas por todas as colônias do reino português. A Universidade de Coimbra (1772), talvez tenha sido sua reforma mais conhecida, e também foram criadas universidades de Matemática e Filosofia (PAIM, 1984). 
A Filosofia nestas universidades mantinha ainda o caráter propedêutico, "nos cursos de medicina, teologia, direito e cânones, porém, assumiu um outro, o do ensino das ciências naturais como um fim em si mesmo" (CUNHA apud ALVES, 2002, p.14).

Com os olhos voltados para produção, a filosofia é compreendida como ciência natural, possuindo um caráter prático $e$ utilitário implantado pela ideologia burguesa, isto é:

[...] passou a demandar a educação que tivesse domínio da natureza pela ciência, no sentido de que 'a observação e a experimentação' são recursos para produção de conhecimento e instrumentos, mediações essenciais para intensificação do domínio do homem sobre a natureza (ALVES apud ALVES, 2002, p.14).

Com isso, tanto Portugal como suas colônias intensificaram o processo de produção com a criação de indústrias e novas tecnologias, e também na preparação de uma mão-de-obra qualificada voltada para produção e para ideologia da época.

Com relação ao ensino de filosofia, a faculdade deveria ser cursada em quatro anos obedecendo às cadeiras na seguinte ordem: 1- Filosofia racional e moral; 2História natural; 3- Física experimental; 4Química teórica e prática. Além de se cur- sar Geometria elementar na faculdade de Matemática nos últimos anos. Tendo em vista que as ideias pombalinas se contrapunham às da Cia. de Jesus, os jesuítas foram expulsos do Brasil e todas as estruturas educacionais organizadas por eles foram destruídas. Entretanto, o Marquês cometeu um enorme erro em não preparar uma estrutura alternativa para o ensino para receber as novas ideias. Com este desmonte da estrutura pedagógica jesuítica (escolas, professores, material didático, etc.) e sem nenhuma base para suprir esta falta, isto é, uma estrutura alternativa de ensino, estas reformas foram mais prejudiciais à educação do que positivas (BARROS, 1997).

Esclarecedora, neste sentido, a lição de Cunha (apud ALVES, 2002, p.15):

\footnotetext{
Se antes, havia nos colégios dos padres jesuítas um plano sistematizado e seriado de estudos, organizados segundo uma pedagogia consistente, a Ratio Studiorum, a reação contra eles, baseada no enciclopedismo, não conseguia erigir um edifício cultural alternativo, ao menos na esfera do ensino.
}

Os novos cursos deveriam ocorrer através das chamadas "Aulas Régias", ou seja, aulas avulsas e isoladas que necessariamente não dependiam da existência de escolas para ministrarem os cursos, o que contribuiu ainda mais para a baixa quali- 
dade do ensino. "Mesmo com a expulsão dos jesuítas no final do século XVIII, o ensino de Filosofia continuou parcelado, fragmentário e de baixo nível" (CARTOLANO apud ALVES, 2002, p. 34).

O Bispo Azeredo Coutinho, ainda tentou implantar uma proposta alternativa de educação com a reativação do Seminário de Olinda (1800), que mesmo sendo padre "nunca deixou, contudo, de raciocinar como um burguês" (ALVES, 2002, p.16), voltou seus estudos para um projeto de educação que preparasse homens para descobrir, inventariar as riquezas naturais do reino, ou seja, seu pensamento estava voltado para solução de problemas práticos e econômicos, um raciocínio centrado na "necessidade do domínio material, para que sejam desenvolvidos [...] a indústria, a agricultura e a mineração" (ALVES apud ALVES, 2002, p.17).

Devido à grande extensão da Colônia, era necessário formar filósofos naturalistas, "homens preparados para cumprir estas tarefas, um especialista em ciências naturais, agentes da modernização econômica, aprenderiam a toda sorte conhecimentos úteis à agricultura e à mineração" (ALVES, 2002, p. 18).

No Seminário de Olinda, o curso de Filosofia estava estruturado da seguinte forma: o curso possuía dois anos de duração, no primeiro ano se estudava a lógica, a metafísica e a física experimental, enquanto no segundo ano estudava-se história natural e química (ALVES, 2002).

Durante o Império até meados do período da independência (1808-1822), o ensino escolar no Brasil não passou por grandes transformações em sua estrutura educacional, praticamente permaneceu com a mesma estrutura desde as reformas realizadas pelo Marquês de Pombal. Após a independência, passou a existir dois setores na estrutura escolar desta época: o estatal (secular), e o particular (religioso e secular), cabendo ao Estado organizar somente o ensino estatal que estava sob sua responsabilidade, já o ensino particular seguia o regime do "laissez-faire". A filosofia esteve sempre presente na escola, no entanto no ensino superior, possuía caráter propedêutico nos cursos de Teologia e Direito (ALVES, 2002).

Segundo Aranha (1998, p. 3), com a criação dos cursos jurídicos no Brasil, na década de 1820, a filosofia torna-se um preceito no ensino médio, "como prérequisito para o ingresso ao curso superior, reforçando o caráter propedêutico que sempre marcou o secundário". 
Segundo Alves (2004), o sistema escolar do período imperial exigia exames parcelados e preparatórios a fim de que os estudantes pudessem ter acesso aos níveis superiores do ensino. Era uma maneira alternativa para aqueles alunos que desejavam cursar o ensino superior e não concluíram o curso secundário ou que não frequentaram as aulas régias ou avulsas. Realizada a matricula nos cursos preparatórios, e após ser aprovado nos exames, encaminhava-se esse aluno para frequentar o curso escolhido. Exemplificando, caso este aluno almejasse frequentar o curso de direito, realizava provas de latim e francês, retórica, filosofia racional e moral, aritmética e geometria. Referente à Filosofia, "a Filosofia Racional forneceria ao estudante um meio de pensar, aquilatar o acerto ou o erro das proposições, a Filosofia Moral seria o primeiro degrau para o estudo do direito natural, a base da jurisprudência" (ALVES, 2002, p.22).

No Colégio Pedro II (RJ), único estabelecimento de ensino secundário de referência do Império, predominava no plano de estudos (da escola) os conteúdos literários (literatura clássica), todavia, estavam presentes as disciplinas de matemática, línguas modernas, as ciências e história. Estas disciplinas estavam distribuídas em oito séries, devendo ser cursadas no prazo de oito anos. Desta forma, o aluno era aprovado por série e não por disciplinas isoladas. A Filosofia constava nas $5^{\mathrm{a}}$ e $6^{\mathrm{a}}$ séries da escola, juntamente com a retórica e a poética, história, matemática, astronomia e a física (BARROS, 1997).

Em 1841, a escola Pedro II passou por uma reestruturação em seu estatuto, diminuindo para sete anos de estudos, aumentando a presença dos estudos literários. O último ano do curso caracterizava-se por um currículo exclusivamente enciclopedista, com estudos da língua grega, alemã, latina, francesa e inglesa; geografia, matemática, história, retórica e filosofia; desenho e música. Esse quadro melhorou quando, com o regulamento de 1855, a filosofia passou a ser ministrada nos três últimos anos de ensino, tendo como conteúdo programático "filosofia racional e moral", "sistemas comparados" e "história da filosofia". Na reforma realizada em 1862, a filosofia ficou reduzida novamente a dois anos, e, posteriormente, com a reforma de 1876, passou para um ano (ALVES, 2002).

No ano de 1883, Sílvio Romero (18511914) legou uma importante contribuição publicando um texto onde fazia críticas ao programa de filosofia no ensino secundário, que era o programa do Colégio Pedro II. 
Nesse trabalho, que tem por justo título "A filosofia e o ensino secundário", o autor protesta contra a inclusão da ontologia, da teodiceia, da moral e de outras matérias num curso de filosofia elementar. Em contrapartida, defende que a filosofia no curso secundário deveria reduzir-se ao que chamava de "lógica formal e real", visando dotar o aluno do "conhecimento prático das leis e regras do raciocínio, a posse dos métodos, e da sua aplicação aos diferentes ramos das ciências" (ROMERO apud BARROS, 1997, p. 95).

No período republicano, as influências positivistas penetraram fortemente no país ao final do século XIX, constituindo a ideologia do movimento republicano. No campo educacional, destaca-se a reforma empreendida por Benjamin Constant, na busca de formar uma nova elite, para o Estado republicano. Neste momento, o Estado assumiu de vez a educação pública escolar, tornando-a laica e sem a intervenção da igreja. Desta forma, Constant garantiria, sem nenhuma interferência, as ideologias do Estado. No tocante à Filosofia, é neste período que ela desaparece pela primeira vez do currículo educacional brasileiro (BARROS, 1997).

O decreto $\mathrm{n}^{\circ} 981$ de 8 de novembro de 1890 altera o currículo escolar ao intro- duzir apenas as disciplinas cientificas e colocando a Filosofia no ostracismo. "Benjamin Constant propõe uma redistribuição de disciplinas nas séries, conforme a hierarquia de Augusto Comte: português, latim, grego, [...], matemática, física, [...], história universal, história do Brasil, [...], ginástica, evoluções militares e esgrima e música" (ALVES, 2002, p. 27). Desta forma, pela primeira vez a filosofia fica fora do currículo, iniciando-se a partir daí, um processo de presença e ausência no currículo escolar secundário.

Posteriormente, uma nova reformulação do regulamento do Ginásio Nacional, realizada em 1898, reintroduziu a disciplina sob a forma de história da filosofia, a ser ministrada no $7^{\circ}$ ano do curso clássico. Mas já em 1899, durante o governo de Campos Salles, houve uma aproximação muito grande das ideias preconizadas por Silvio Romero em seu trabalho de 1883, quando pelo Decreto $\mathrm{n}^{\circ} 3251$ de 08 de abril de 1899, impõe-se outro regulamento ao Ginásio Nacional, reduzindo o curso de sete para seis anos, ao mesmo tempo em que substituía a história da filosofia pela lógica (BARROS, 1997).

Em 1901, com a reforma de Epitácio Pessoa, a Filosofia é reincluída no $6^{\circ}$ ano 
do ensino secundário (lógica) e de 1910 a 1914, novamente é retirada do currículo.

No ano de 1915, a Reforma de Carlos Maximiliano consolida o utilitarismo do ensino secundário, definindo a obrigatoriedade das disciplinas como português, francês, história do Brasil, física e química. A Filosofia foi inserida de forma facultativa ao currículo (ALVES, 2002).

Já em 1925, a Reforma Rocha $\mathrm{Vaz}^{2}$, defendia um ensino secundário que fornecesse uma cultura geral, desprendida da escolha profissional, ou seja, um ensino que preparasse para vida, um ensino mais humanista. O ensino neste período foi dividido em seis séries no qual a filosofia foi incluída nas duas últimas séries sob o eixo da filosofia da história. Porém, não chegou a atender as perspectivas, pois a filosofia foi deslocada "[...] para um conjunto de doutrinas (católicas), noções e conceitos destinados a manter a ordem social vigente e os interesses de grupos minoritários e dominantes políticos" (HORN, 2000, p. 25).

Com o golpe de 1930, no qual as grandes oligarquias foram destituídas e,

${ }^{2}$ Tornou os currículos escolares seriados, elaborando programas oficiais e restituindo bancas examinadoras para o ensino particular. Decreto n. ${ }^{\circ} 16.782$ A, de 13 de janeiro de 1925. Estabelece o Concurso da União para a difusão do ensino primário, organiza o Departamento Nacional do Ensino, reforma o ensino secundário e o superior e dá outras providências (VALENTE, 2012, online). dada a necessidade de se criar condições para implantação do capitalismo industrial, Vargas efetuou um conjunto de reformas para dar sustentação política $e$ ideológica para seu governo. No que se refere ao campo educacional, podemos destacar aquelas que possuem relação diretamente com o ensino secundário: a reforma Francisco Campos (1932) e a mais importante, a Reforma Gustavo Capanema (Lei orgânica do ensino secundário de 1942). Um dos motivos que nortearam essas reformas se deu pela necessidade de qualificar a mãode-obra para o segmento industrial (BARROS, 1997).

As medidas mais importantes tomadas durante a reforma Francisco Campos foram: criação de um regime seriado de estudo e a frequência obrigatória. A estrutura dos cursos secundários foi dividida em dois ciclos, quais sejam: Fundamental, em cinco anos, e Complementar, em dois anos. No que tange a filosofia, passou a fazer parte do currículo do ensino complementar, sendo dadas aulas de história da filosofia $e$ lógica.

Durante a reforma Capanema, o ensino manteve o mesmo caráter enciclopedista e elitista da reforma passada, como também, dividida em dois ciclos: o secundário (ginásio) com a duração de quatro anos, $e$ 
o colegial, com a duração de três anos, este subdividido em dois cursos paralelos: o clássico, que enfatiza a formação intelectual, e o cientifico, enfatiza o estudo das ciências. Neste período, a Filosofia tinha lugar obrigatório na $2^{\mathrm{a}}$ e $3^{\mathrm{a}}$ séries do curso clássico e no $3^{\circ}$ ano do científico.

Tanto no curso clássico como no cientifico a Filosofia era ensinada com base no programa, tendo apenas maior amplitude no último ano científico. O programa subdividia-se em alguns capítulos: introdução, objeto e importância da Filosofia; sua divisão; lógica, estética, psicologia, moral, sociologia e cosmologia. A lógica, a moral $e$ a sociologia tinham espaços privilegiados nas aulas de Filosofia do $3^{\circ}$ ano do curso clássico. Mas em 1954, a portaria n.54 reduziu o número de aulas semanais, estabelecendo um mínimo de duas horas por semana nas séries do clássico e uma hora apenas, no científico (HORN, 2000, p. 27).

Após essas reformas, e mais principalmente a Capanema, que representou um avanço para a obrigatoriedade da disciplina filosofia no currículo escolar, surge à lei $\mathrm{n}^{\circ}$ 4.024/61, a primeira Lei de Diretrizes e Bases da Educação Nacional, que coloca no currículo escolar um caráter meramente complementar para a disciplina Filosofia, ficando a critério dos Conselhos Estaduais a permanência ou não no currículo escolar, sendo ela dada apenas no colegial. Com esta lei, o ensino de filosofia perdia a obri- gatoriedade, tornando-se disciplina complementar, ou seja, incorporada mediante indicação de cada Conselho Estadual de Educação. Apesar de poder figurar como disciplina optativa, tanto no ginasial, quanto no colegial, a filosofia, ainda ausente dos vestibulares, praticamente desapareceu do ensino em detrimento de uma ênfase às disciplinas que eram cobradas nos vestibulares (ALVES, 2002).

Já o Conselho Federal de Educação tornou possível aos estados e às instituições de ensino anexarem disciplinas opcionais ao currículo mínimo estabelecido, representando um avanço em termos de legislação. Porém na prática, "as escolas acabaram compondo o seu currículo de acordo com os recursos materiais e humanos de que já dispunham, ou seja, continuaram mantendo o mesmo currículo de antes" (ROMANELLI apudBARBOSA, 2005, p.32).

Nesse período, a política educacional continuou enfatizando os princípios liberais e democráticos já estabelecidos na Constituição Federal de 1946. Nessa Constituição, ficou estabelecido no artigo 167 que "o ensino dos diferentes ramos será ministrado pelos poderes públicos e é livre a iniciativa privada, respeitadas as leis que o regulem" (ROMANELLI apud BARBOSA, 2005, p.32). Desta forma, a iniciativa pri- 
vada possuía direitos garantidos pela própria Constituição. Com fulcro nessa Constituição, teve início uma grande discussão, que perdurou por treze anos e culminou na Lei de Diretrizes e Bases da Educação Nacional, de 1961 (BARBOSA, 2005).

Durante o Regime Militar, em 1964, complicou-se ainda mais o quadro da filosofia, que desta vez passa a possuir um caráter optativo, sua presença iria depender apenas da boa vontade ou não da direção escolar. Sabemos que, em se tratando de educação no Brasil, o ensino escolar sempre caminhou em cumplicidade com a ordem política e econômica vigente em cada época de nossa história, então, tanto a estrutura, como o papel educacional das escolas brasileiras estava voltado para reproduzirem a ideologia da atual classe dominante. $\mathrm{O}$ governo militar quando assumiu o poder, direcionou a política nacional para atender as necessidades da classe que representava (GHIRALDELLI, 2003).

Para que houvesse justificativa para a retirada da Filosofia, criou-se disciplinas cujos conteúdos supostamente equivalessem aos conteúdos filosóficos (Educação Moral e Cívica, Organização Social e Política do Brasil - OSPB) e, a nível superior, a disciplina Estudos dos Problemas Brasileiros (ALVES apud ANDRADE, 2008).
No regime militar, segundo Alves (apud ANDRADE, 2008), a Filosofia não mais era entendida como uma disciplina sem relevância, e sim como uma disciplina subversiva. Isso fez com que fosse extinta definitivamente no ano de 1968.

O fato novo, inusitado, na atitude dos Governos Militares, é que, enquanto nos períodos anteriores se postulava a retirada da filosofia do currículo por ela ser considerada conservadora $e$ identificada com o ideário clerical, monárquico, contra o qual se fundou a República Brasileira; os Militares a retiravam por ser subversiva, devido ao seu potencial revolucionário, isto é, por insuflar as massas (de estudantes) contra o "Regime" em vigência naquele tempo (ALVES apud ANDRADE, 2008, p. 05).

Alves (2004 apud ANDRADE, 2008) ressalta que a semelhança entre a Filosofia e essas disciplinas não é factível, mas uma mera justificativa para a existência destas em detrimento da primeira. Vale ressaltar que as "disciplinas correspondentes" eram obrigatórias e a Filosofia optativa, tornando a presença da última mais rara.

Assim começaram diversas reações a favor da Filosofia na educação básica. Segundo Alves (apud ANDRADE, 2008, p. 06-07): 
Esta atitude, porém, ocasionou, em contrapartida, uma reação inédita na história do ensino de filosofia no Brasil, por parte dos profissionais da área e de educadores, políticos, estudantes etc. Jamais se tinha visto tamanha manifestação a favor da filosofia e de seu ensino tal como nesse período. Foram organizados, nas regiões e em todo território nacional, movimentos de protesto, seminários, congressos, publicações de livros e artigos em jornais, reivindicando a volta da filosofia como disciplina obrigatória no currículo. Fundaram-se, inclusive, associações e sociedades filosóficas com representatividade nacional, a partir dos departamentos de filosofia das universidades.

Entretanto, a Filosofia enquanto disciplina reflexiva, que ensinava o homem a ter uma autonomia de pensamento, que tem como força motriz formar cidadãos com consciência crítica, que dessa forma pudessem refletir e questionar a sua realidade passou a constituir uma enorme ameaça à ordem vigente. Um outro motivo que cooperou para o desaparecimento da Filosofia se deveu aos acordos MEC e Usaid (Agência Norte-Americana para o Desenvolvimento Internacional). Nestes acordos, o EUA se propôs a "ajudar" a educação brasileira. "Sob o signo do desenvolvimento realizou-se a inclusão das disciplinas técnicas no currículo, o que exigiu a exclusão de outras, a exemplo da filosofia" (HORN, 2000, p.28). Então o país passou a receber auxílio financeiro que acabou resultando nas Leis $\mathrm{n}^{\circ} 5.540 / 68$ (ensino universitário) e a $n^{\circ}$ 5692/71 (HORN, 2000).

A Lei $n^{\circ} 5692 / 71$ foi criada para atender a uma demanda econômica do capital nacional e multinacional, que precisava de mão-de-obra qualificada e especializada, porém, barata para as indústrias, daí o caráter profissionalizante que foi adquirindo o ensino secundário. A filosofia foi substituída por disciplinas como EMC (Educação Moral e Cívica) e OSPB (Organização Social e Política Brasileira), que se vinculavam à ideologia dominante e tinham caráter obrigatório em todas as escolas. Os conteúdos trabalhados por essas disciplinas eram: valores fundados na moral católica, do civismo, a obediência às leis e o respeito à família. E como os conteúdos sobre "a moral" também eram trabalhados pela Filosofia, foi descartada mesmo assim por não ser considerada uma disciplina obrigatória (GHIRALDELLI, 2003).

Três acontecimentos podem ser destacados neste período. O primeiro foi a fundação, no ano de 1975 do Centro de Atividades Filosóficas, que no ano de 1984 foi chamada de Sociedade de Estudos e Atividades Pedagógicas (SEAF); esse acontecimento foi um marco nos movimentos que defendiam que a Filosofia retornasse aos currículos. O SEAF "conferiu um caráter 
mais articulado a esses movimentos" (ALVES apud ANDRADE, 2008, p. 06).

O segundo acontecimento é o fato de que devido aos protestos contrários à política educacional vigente, no ano de 1980, a Filosofia foi reintroduzida nos currículos do Rio de Janeiro, intitulada "noções de Filosofia". Nessa reintrodução, o Governo se preocupou em controlar o ensino da disciplina, passando a monitorar os professores, programas $e$ até as fontes bibliográficas (ANDRADE, 2008).

O terceiro e último acontecimento foi estender os procedimentos que foram adotados no estado do Rio de Janeiro para toda a União (ANDRADE, 2008).

No entanto, em nível federal, a volta da Filosofia ao cenário escolar não foi obrigatório. Citando Renê Silveira, Alves (apud ANDRADE, 2008) alerta para a existência de novas barreiras a serem transpostas pela disciplina. A decisão de inserir ou não a disciplina no currículo caberia à escola. Isso fez com que ficasse difícil reimplantar a Filosofia, tendo em vista que ela teria de ser inserida na grade horária regular, que, no entanto, não seria ampliada, ocasionando consequentemente resistências por parte de docentes de outras disciplinas que não desejavam que suas cargas-horárias fossem reduzidas para não ter seus salários reduzi- dos e para não ser necessário distribuírem suas aulas em mais de uma escola. Também, o processo de atribuição de aulas podia ser amplamente manipulado, viabilizando que os diretores das escolas dessem as aulas de Filosofia àqueles professores que melhor lhe conviessem. Não obstante a questão da obrigatoriedade, que se constitui em um problema de legitimidade institucional, havia também o problema das aulas não serem ministradas por professores com licenciatura plena em Filosofia, o que subvertia a especificidade da disciplina.

Com o advento da abertura política, lenta e gradual, aproximadamente no final da década de 70, o quadro político brasileiro começou a se transformar. No ano de 1978, foi constituído o Comitê Brasileiro pela Anistia, que objetivava trazer de volta ao Brasil aqueles que foram exilados no período do regime militar. Apoiando esse movimento, diversas entidades, como,por exemplo, a OAB (Ordem dos Advogados do Brasil), Comissão de Justiça e Paz da CNBB (Conferência Nacional dos Bispos do Brasil), manifestaram-se favoráveis à anistia e retorno ao estado de direito no país (BARBOSA, 2005).

No começo dos anos 80, o autoritarismo do regime militar no Brasil já havia se esgotado. Em 1983, a partir da Lei 7044, 
de 18 de outubro de 1982, as instituições de ensino deixaram de ser obrigadas a oferecer a habilitação profissional, imposição contida na Lei 5692/71 (BARBOSA, 2005)

Apesar das grandes conquistas políti$\operatorname{cas}^{3}$ observadas nesse período, será a partir da instalação da Assembleia Nacional Constituinte, em 1987, que foi possível assistir a intensos debates no campo da educação.

Após quase dois anos de trabalho da Assembleia, presidida pelo Deputado Ulysses Guimarães, foi promulgada a nova Constituição brasileira, em 05 de outubro de 1988. Ela trouxe o reconhecimento do direito de voto aos analfabetos, do direito de greve, a oficialização do fim da censura e tornou a tortura crime inafiançável, entre muitas outras mudanças. Em relação à educação, incluiu parcialmente os princípios propostos pelo Fórum da Educação na Constituinte. Princípios que indubitavelmente, representaram avanços em relação aos textos constitucionais anteriores.

Com a promulgação de uma nova Constituição, uma nova lei geral para a educação se fez necessária, uma lei que tornasse compatível a Educação com a nova Constituição. Em 1988 foi proposto o

\footnotetext{
${ }^{3}$ Reforma partidária (1979); eleições diretas para governadores (1982); eleições para deputados e senadores (1986)
}

Projeto de Lei $n^{\circ} 1258 / 88$, primeiro projeto completo de uma nova Lei de Diretrizes e Bases. A redação desse projeto, datada de 1993, dispunha em seu art. 48 que as disciplinas Filosofia e Sociologia passariam a ser disciplinas obrigatórias no ensino médio - como passou a ser denominado o antigo $2^{\circ}$ grau. Assim, "o currículo do ensino médio observará [...] as seguintes diretrizes: [...] IV - serão incluídas a filosofia e a sociologia como disciplinas obrigatórias" (PL 1258/88 apud BARBOSA, 2005, p.37).

No entanto, como nesse período a obrigatoriedade encontrava-se ainda em forma de projeto, a única possibilidade realmente concreta de inclusão da filosofia no currículo de $2^{\circ}$ grau (atual ensino médio) continuava vinculada à parte diversificada permitida pela Lei 5692/71, ainda vigorando naquele momento.

Barbosa (2005, p.37-38) explica que:

Numa espécie de compensação pelos muitos anos de dilapidação oficial, a Portaria $\mathrm{n}^{\circ} 399$, de 28 de junho de 1989, amplia o campo de atuação dos professores dessa disciplina. Por esta portaria, aos licenciados em filosofia seria concedido registro de professor de "filosofia no $2^{\circ}$ grau, psicologia e sociologia no $2^{\circ}$ grau $e$ história no $1^{\circ}$ e $2^{\circ}$ graus".

Durante seis anos, um difícil processo de elaboração da Lei de Diretrizes e Bases 
para a Educação envolveu inúmeros segmentos da sociedade brasileira. O texto inicial do Projeto de Lei $n^{\circ} 1258 / 88$ foi emendado muitas vezes, até resultar no projeto final, enviado em 1994 pela Câmara ao Senado (BARBOSA, 2005).

No momento atual, o problema da filosofia reaparece com a nova $\mathrm{LDB}$, Lei $\mathrm{n}^{\circ}$ 9.394/96, que reintroduz a Filosofia no Ensino Médio, porém não caracteriza objetivamente como sendo obrigatória no currículo escolar. O artigo 36, da seção IV, capítulo II, título $\mathrm{V}$, que expõe sobre o currículo do ensino médio, menciona no $1^{\circ}$ parágrafo, inciso III: "Os conteúdos e as formas de avaliação serão organizadas de tal forma que ao final do ensino médio o educando demonstre [...] domínio dos conhecimentos de filosofia necessários ao exercício da cidadania" (BRASIL, 1996). Desta forma, a lei demonstra seu caráter ambíguo no que se refere ao ensino de filosofia, pois a lei não explicita e nem deixa claro como serão efetivados os "conhecimentos de Filosofia", se será uma disciplina obrigatória ou apenas como temas transversais em outras disciplinas.

Como se pode notar, desde o Brasil Colônia, até o momento atual, a Filosofia sempre vem lutando para realmente conquistar seu lugar de destaque no currículo educacional brasileiro, principalmente no que diz respeito ao Ensino Médio. Ela precisa conquistar seu lócus, tanto no campo político-institucional, como na plena efetivação no currículo. Não deve esta disciplina, como aconteceu no seu passado, limitar-se apenas a passar e reproduzir pensamentos, ideias e teorias dogmatizando o conhecimento de alguns pensadores como verdades absolutas, inviabilizando que o educando fomente em sim um pensamento voltado para reflexão crítica da realidade que o cerca, o seu meio, sua sociedade, sua história e sua cultura.

A Lei de Diretrizes e Bases da Educação Nacional 9.394/96 não apresentou nenhum parágrafo assegurando a obrigatoriedade do ensino de Filosofia. No entanto, o documento propõe na sessão IV, artigo 36 , inciso III que ao final do ensino médio o educando demonstre: "domínio dos conhecimentos de filosofia e de sociologia necessários ao exercício da cidadania" (BRASIL, 1996). É só em 2008, com a lei n. 11.684 de autoria do Deputado Federal Ribamar Alves (PSB-MA), que a Filosofia (juntamente com a Sociologia) passa a ser incluída como disciplina obrigatória nos currículos do Ensino Médio, embora essa obrigatoriedade não exista (ainda!) para o Ensino Fundamental. 


\section{REFERÊNCIAS}

ALVES, D. J. A filosofia no ensino médio: ambigüidade e contradições na LDB. Campinas: Autores Associados, 2002.

ANDRADE, F R. "Não sei por que tanto por quê?" A Filosofia como Disciplina no Primeiro Ciclo no Ensino Fundamental da Rede Municipal de Barueri (1997-2005). 147f. (Dissertação de Mestrado). São Paulo, Faculdade de Educação da Universidade de São Paulo, 2008.

ARANHA, M. L.; MARTINS, M. H. Temas de filosofia. 2. ed. São Paulo: Moderna,

BARBOSA, C. L. A. A Filosofia no Ensino Médio e suas Representações sociais. 185f. (Dissertação de Mestrado). Niterói, Universidade Federal Fluminense, 2005.

BARROS, R. S. M. Estudos brasileiros. Londrina: Editora da UEL, 1997.

BRASIL. Lei ${ }^{\circ}$ 11.684/08. Altera o art. 36 da Lei no 9.394, de 20 de dezembro de 1996, que estabelece as diretrizes e bases da educação nacional, para incluir a Filosofia e a Sociologia como disciplinas obrigatórias nos currículos do ensino médio. Brasília, 2008. Disponível em $<\quad$ http://www.planalto.gov.br/ccivil_03/_Ato2007-2010/2008/Lei/L11684.htm >> Acesso em Junho de 2015.

BRASIL. Lei $n^{\circ}$ 9.394, de 20 de Dezembro de 1996. Disponível em: <http://www.planalto.gov.br/ccivil_03/leis/19394.htm>Acesso em Junho de 2014.

GHIRALDELLI, Jr. P. Filosofia e história da educação brasileira. São Paulo: Monale, 2003.

HORN, G. B. A presença da filosofia no currículo do ensino médio brasileiro: uma perspectiva histórica. In: GALLO, S.; KOHAN, W. O. (Orgs.). Filosofia no ensino médio. Petrópolis: Vozes, 2000.

VALENTE, N. As principais reformas da educação brasileira. (2012). Disponível em <http://prtb.org.br/2012/10/03/as-principais-reformas-na-educacao-brasileira/> Acesso em Julho de 2015.

Recebido em: 13/04/2016 Aprovado em: 31/10/2016 